\title{
Formação De Professores De Ciências No Brasil E Alfabetização Científica: Desafios E Perspectivas
}

\section{Training of Science Teachers in Brazil and Scientific Literacy: Challenges and Perspectives}

\author{
Helena Amaral da Fontoura* \\ (iD) http://orcid.org/0000-0003-2795-8246 \\ Elienae Genésia Corrêa Pereira ${ }^{* *}$ \\ (iD) http://orcid.org/0000-0003-1919-8785 \\ Sandro Tiago Figueira ${ }^{* * *}$ \\ (iD) http://orcid.org/0000-0001-5351-0782
}

Tipo de Artículo: Informes de Investigación y ensayos inéditos

Doi: 10.17533/udea.unipluri.20.1.07

Cómo citar este artículo:

Fontoura, H., Pereira, E. G. C., y Figueira, S. T. (2020). Formação de Professores de Ciências no Brasil e Alfabetização Científica: desafios e Perspectivas. Uni-Pluriversidad, 20(1), e2020106. doi: 10.17533/udea. unipluri.20.1.07

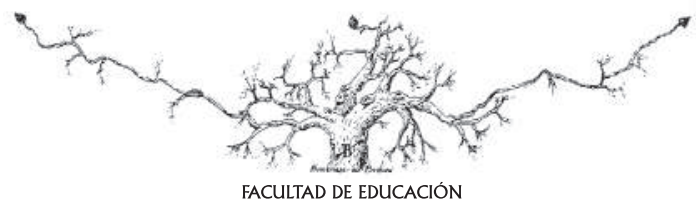

Recibido: 2019-10-28 • Aprobado: 2020-08-15

* $\quad$ Faculdade de Formação de Professores -UERJ. Brasil

Email: helenafontoura@gmail.com

** Faculdade de Formação de Professores -UERJ. Brasil Email: elienaep@gmail.com

*** Secretaria Municipal de Educação do Rio de Janeiro (SMERJ), Rio de Janeiro, RJ, Brasil. Email: figueiras.tiago@gmail.com 


\title{
Resumo
}

O presente trabalho traz uma reflexão sobre o conceito de alfabetização científica e sua importância no ensino de Ciências. Para tal, discute processos formativos de docentes da área, com base em autores importantes para sua compreensão, trazendo uma base conceitual sólida para discutir a questão principal. Uma densa revisão de literatura consubstancia as posições refletidas, quais sejam: a importância de esclarecer o conceito de alfabetização científica, sua articulação com a formação de professores de Ciências, e o desafio de pensar uma relação de ensino-aprendizagem que seja referenciada na superação de um paradigma tradicional que não articule os desafios da vida moderna e que traga perspectivas para uma educação de qualidade e que desenvolva o pensamento científico, a cidadania, a vida em cooperação e uma sociedade mais justa, que cuide do ambiente em que vive e contribua para a superação das desigualdades sociais. Pensar uma didática de ciências que se apodere das tecnologias sem deixar a dimensão humana e social é desafio que se apresenta para professores e alunos em processo de se alfabetizarem cientificamente.

Palavras chave: Alfabetização Científica; Formação de professores de Ciências; Ensinoaprendizagem.

\begin{abstract}
The present work brings a reflection on the concept of scientific literacy and its importance in science teaching. To this end, it discusses formative processes of teachers in the area, based on authors important for their understanding, bringing a solid conceptual basis to discuss the main issue. A dense literature review embodies the reflected positions, which are: the importance of clarifying the concept of scientific literacy, its articulation with the training of science teachers, and the challenge of thinking about a relationship of teaching-learning that is referenced in overcoming a traditional paradigm that does not articulate the challenges of modern life and that brings perspectives to quality education and that develops scientific thinking, citizenship, life in cooperation and a fairer society, which takes care of the environment in which it lives and contributes to overcoming social inequalities. To think of a didactic science that takes over technologies without leaving the human and social dimension is a challenge that presents itself for teachers and students in the process of scientifically literacy.
\end{abstract}

Keywords: Scientific Literacy; Training of science teachers; Teaching-learning. 


\section{Resumen}

El presente trabajo hace una reflexión sobre el concepto de alfabetización científica y su importancia en la enseñanza de la ciencia. Con este fin, analiza los procesos formativos de los profesores en la zona, basados en autores importantes para su comprensión, aportando una base conceptual sólida para discutir el tema principal. Una densa revisión de la literatura encarna las posiciones reflejadas, que son: la importancia de aclarar el concepto de alfabetización científica, su articulación con la formación de los profesores de ciencias, y el desafío de pensar en una relación de enseñanza-aprendizaje al que se hace referencia para superar un paradigma tradicional que no articula los desafíos de la vida moderna y que aporta perspectivas a una educación de calidad y que desarrolla el pensamiento científico, la ciudadanía, la vida en cooperación y una sociedad más justa, que cuida el medio ambiente en el que vive y contribuye a superar las desigualdades sociales. Pensar en una ciencia didáctica que se apodera de las tecnologías sin salir de la dimensión humana y social es un reto que se presenta para profesores y estudiantes en el proceso de alfabetización científica.

Palabras-clave: Alfabetización científica; Formación de profesores de ciencias; Enseñanzaaprendizaje. 


\section{INTRODUÇÃO}

Vivemos em uma sociedade complexa onde mudanças socioculturais e tecnológicas têm ocorrido de forma acelerada e contínua, tendo em vista que, direta ou indiretamente, todas as peculiaridades do cotidiano e das vidas de cada um de nós são abarcadas e influenciadas pelo crescente conhecimento científico, fazendo-se necessário às crianças, jovens e adultos o entendimento de suas aplicações e implicações.

Diante deste contexto, é oportuno destacar que os estudantes estão vivendo em um mundo globalizado e sintonizado a uma gama de informações que chegam a eles por inúmeras fontes, sendo imperioso à escola conhecer esse 'novo mundo', não cabendo mais oferecer um ensino de Ciências focado e baseado em metodologias que se preocupem meramente na memorização de fórmulas, leis e teorias, pois, conforme defendem Damásio e Peduzzi (2018, p. 15), em tempos de uma sociedade caracterizada por mudanças drásticas e rápidas, "desconstruir a rigidez de conceitos como certeza, verdade, dicotomias de entidades isoladas, de causalidade simples e autoridade parece ser uma função bastante importante para a escola, e por consequência, do docente". Em uma sociedade inovadora, o compromisso de preparar seus cidadãos para receber e compreender as mudanças, adaptando-se a elas e influenciando nas decisões que precisam ser tomadas, é essencial (UNESCO, 2008).

Assim, escola e professores têm a missão preponderante e indispensável no que tange à informação e à discussão crítica quanto à sociedade, ao ambiente e ao indi- víduo, pois, enquanto instituição de ensino, pode gerar mudanças comportamentais nos discentes (Krasilchick, 2005), fazendo com que relacionem suas escolhas não apenas à sua vida pessoal, mas também às questões socioambientais e políticas, em um movimento interativo e contínuo, despertando e estimulando uma constante curiosidade e busca de novos conhecimentos e práticas, preferencialmente de modo descontraído, lúdico e prazeroso. Na escola, local que centraliza a prática docente, os alunos podem aprender a se relacionar e a desenvolver o senso crítico, a autoestima e a segurança (Bydlowski, Lefévre, Pereira, 2011), pois o professor, com sua prática em sala de aula, possui grande potencial para transformar a realidade, sensibilizando o aluno para essa mudança, através de propostas e ações contextualizadas (Freire, 2002).

Os autores já trazem um lastro de produções que transversalizam os temas propostos (Pereira, 2015, Pereira, e Ferrão-filho, 2017, Pereira, Fontoura, 2013, 2015a e 2015b; Pereira, Pedrini, Fontoura, 2019a e 2019b, Pereira, Santos, 2016, Figueira, Fontoura, 2018, Figueira, 2019). Trabalharemos aqui na articulação entre formação de professores de Ciências e o conceito de alfabetização científica, visando contribuir para processos formativos docentes mais relacionados aos avanços do conhecimento nas áreas de Ciências e nas preocupações que trazemos de alimentar a docência referenciada dos que se dedicam à profissão de professor.

Antes, porém, esclareceremos como entendemos alfabetização científica, visto que a 
literatura se utiliza também de outros termos para definir a educação em Ciências voltada para a formação integral do cidadão atuante na sociedade de forma crítica e consciente: letramento científico e enculturação científica são alguns termos.

\section{AlfabetizaÇão Científica: discussão Semântica}

A variedade semântica que permeia o conceito de alfabetização científica advém, a princípio, da tradução da expressão da língua inglesa 'scientific literacy', ora para alfabetização científica ora para letramento científico, pois tanto na língua espanhola quanto na francesa, os termos usados são correspondentes à alfabetização: 'alfabetización científica' e 'alphabétisation scientifique', sendo traduzidos desta forma.

$\mathrm{Na}$ esfera internacional, o termo 'scientific literacy' foi citado pela primeira vez em 1958, por Paul Hurd, sendo seus trabalhos importantes para a consolidação desse conceito (Sasseron, Carvalho, 2011). Segundo Cunha (2017), internacionalmente esse termo foi usado pela primeira vez em 1996, pelo então presidente da Associação Americana para o Progresso da Ciência, no World Science Report, relatório da UNESCO, explanando que 'scientific literacy' é um trabalho diário de conhecimento da Ciência, essencial como a leitura e a escrita para uma vida satisfatória no mundo moderno propiciando o bem-estar econômico e saudável do tecido social e de cada pessoa e para o exercício da democracia participativa (Ayala, 1996, apud Cunha, 2017).

Se considerarmos a semântica da palavra 'literacy', seu significado (na língua inglesa) corresponde à 'capacidade de ler e escrever' ou 'ser/estar alfabetizado', sendo sua tradução direta 'alfabetização'. Cabe salientar que o conceito de literacy/alfabetização, na época em que surgiu, ainda dentro das ciên- cias linguísticas, estava atrelado à visão positivista-tecnicista, visando principalmente o ato de ler-escrever, mas já vislumbrando sua ampliação para um conceito maior que inserisse a compreensão das diversas formas de representação e uso da linguagem e o uso da prática social da leitura e da escrita (Grando, 2012).

Autores brasileiros que fazem uso da nomenclatura 'letramento científico' (como Mamede, Zimmermann, 2007, Santos, 2007, Santos, Mortimer, 2001) se baseiam no que postulam Kleiman e Soares, pesquisadores da Linguística (Sasseron, Carvalho, 2011), quanto ao significado de letramento: resultado do ato de aprender a ler e escrever e desenvolvimento de comportamentos e habilidades que permitem que o indivíduo se aproprie da leitura e da escrita usando-as em suas práticas sociais (Soares, 2004) enquanto sistema simbólico e tecnologia em contextos e para objetivos específicos (Kleiman, 2008).

É interessante comentar que o termo 'letramento' tem sido usado gradativamente em substituição ao termo 'alfabetismo' (que surgiu na década de 1980 a partir das discussões sobre o analfabetismo) que pode ser encontrado em textos de Soares, como no livro 'Alfabetização e letramento' de 1995 onde a autora traduz 'literacy' como 'alfabetismo', ressaltando a importância histórica desse conceito nas práticas sociais (Grando, 2012).

O termo 'enculturação científica' (adotado por Carvalho, 2007, Mortimer, Machado, 1996, Trivelato, 2011) é mais recente e 
adveio do pressuposto de que a educação em Ciências deve proporcionar condições para que os discentes façam parte de uma cultura onde noções, ideias e conceitos científicos são parte de seu corpus, podendo, assim, carregá-la consigo, obtendo informações, se comunicando e sendo capazes de participar das discussões dessa cultura. Com este pensamento, o objetivo desse ensino de Ciências é a formação cidadã dos alunos para o domínio e uso dos saberes científicos e seus desdobramentos nas mais diferentes esferas de sua vida (Sasseron, Carvalho, 2011).

Os autores que utilizam o termo 'alfabetização científica' (Auler, Delizoicov, 2001, Brandi, Gurgel, 2002, Chassot, 2003, Krasilchik, Marandino, 2004, Lorenzetti, Delizoicov, 2001, Sasseron, Carvalho, 2011) entendem alfabetização de forma ampliada. Para Krasilchik e Marandino (2004) a alfabetização científica deve propiciar, além da capacidade de 'ler a ciência', a sua compreensão e a capacidade de discutir e opinar sobre ela, participando da cultura científica. Chassot (2003, 2006) vê a alfabetização científica como um conjunto de conhecimentos que daria aos indivíduos condições de fazerem uma leitura do mundo onde vivem, contribuindo para o controle e previsão das transformações que acontecem na natureza, conduzindo-as para a melhoria da qualidade de vida socioambiental, como uma forma de fazer a inclusão social. Sasseron e Carvalho (2011), por sua vez, defendem o uso de alfabetização científica apoiadas na ideia de alfabetização emancipatória, postulada por Freire (1980, 2005): o domínio psicológico e mecânico de técnicas de escrever e de ler consciente que resulta em uma postura interferente do homem sobre seu contexto, seu mundo fazendo com que seja capaz de transformá-lo através de uma prática consciente e crítica.
A recente Base Nacional Comum Curricular (BNCC) brasileira utiliza o termo letramento científico para a área de ensino das Ciências Naturais. Homologado no final de 2017 enquanto política pública educacional obrigatória para configuração curricular da Educação Básica, objetiva enfrentar as desigualdades de aprendizagem encontrados em nosso país. O texto da BNCC (Brasil, 2017) define sua matriz, no contexto de letramento científico como um

conjunto orgânico e progressivo de aprendizagens essenciais que todos os alunos devem desenvolver ao longo das etapas e modalidades da Educação Básica, de modo que tenham assegurados seus direitos de aprendizagem e desenvolvimento. (p. 7).

A BNCC relaciona o letramento científico ao termo capacidade e competência para compreender e interpretar o mundo (natural, social e tecnológico), mas também de transformá-lo com base nos aportes teóricos e processuais das ciências (Brasil, 2017). Inferimos que essa conceituação clarifica a tensão que reside no planejamento das aulas de Ciências: a que torna a perspectiva acadêmica voltada para conteúdos e conceitos, e outra mais utilitária, centrada na formação do cidadão compreendendo os conceitos e os utilizando para enfrentar e refletir sobre o seu cotidiano.

Nossos questionamentos enquanto pesquisadores da área de ensino de Ciências centram-se nas contribuições que essa categoria - alfabetização/letramento/enculturação científica - pode conferir à prática pedagógica nos ensinos fundamental e médio brasileiros, uma vez que o termo alfabetização científica já se encontra consolidado nas dinâmicas pedagógicas enquanto movimentos de ensinar e aprender perpassados pelo dar-se conta das responsabilidades, oportunidades e desafios do cotidiano. 
Considerando as premissas apresentadas, é possível constatar que as definições e caracterizações expressas pelos autores que adotam cada um dos termos denotam a mesma essência, mostrando que esses pesquisadores possuem as mesmas preocupações e almejam os mesmos objetivos: uma educação em Ciências abrangente, contextualizada, prática, socializada, que considera as questões socioambientais e culturais e contribua efetivamente na formação de um cidadão atuante na sociedade.

Com este entendimento, optamos por utilizar neste artigo o termo 'alfabetização científica'. Defendemos que o estudo das ciências naturais, nessa perspectiva, tome como sustentação a análise dos benefícios e riscos de cada avanço tecnológico, envolvendo as dimensões ética e socioambiental e superando as polarizações que em nada contribuem para o avanço consciencial dos estudantes.

\section{SOBRE ALFABETIZAÇÃo CIENTÍFICA}

A alfabetização científica e tecnológica, como postulam Cachapuz e colaboradores (2005), alicia e dedica-se não meramente no conceito científico, mas na história da construção desse conceito, discorrendo e refletindo sobre as tensões políticas e sociais nesse desenvolvimento e consolidando o caráter humano dessa construção.

Frente a essa realidade, faz-se necessário a presença nas escolas de profissionais cada vez mais dinâmicos, sintonizados com a sociedade e capazes de refletir sobre suas necessidades e conflitos, repensando sua prática pedagógica de modo a tornar o processo ensino-aprendizagem mais significativo e contextualizado para os alunos, atendendo, ou pelo menos, minimizando a efemeridade do sistema social atual. Da mesma forma, o ensino de Ciências deve ir além dos conteúdos científicos, se afastando de condutas pedagógicas conteudistas e metodologias expositivas, e aproximar-se da sociedade, discutindo suas mudanças em todos os âmbitos, e sintonizar-se com as vivências e saberes dos alunos, tendo o diálogo, as discussões, o pensamento crítico, a cidadania, as questões socioambientais, a expressividade e a criatividade dos discentes como eixos norteadores do processo di- dático-pedagógico. Por outro lado, Fronza (2016) evidencia uma grande distância entre a vivência escolar e a vivência social.

Sob esta ótica, Chrispino (2008) alerta que a dificuldade em promover a alfabetização científica e tecnológica de forma crítica e contextualizada, visando interagir com o meio social para melhor formar o cidadão, talvez se deva às distorções da imagem da Ciência e da Tecnologia, apresentadas por Cachapuz e colaboradores (2005) como a visão descontextualizada, a visão elitista e individualista, a visão empiro-indutivista e a-teórica, a visão rígida e infalível e como a visão a-problemática e a-histórica, distante de uma educação científica que seja útil para a sociedade contemporânea e que proporcione subsídios para o crescimento e amadurecimento de cidadãos mais conscientes e atuantes. Neste sentido, Carvalho e Gil-Pérez (2006) advertem que a ausência, nos currículos escolares, das interações Ciência-Tecnologia-Sociedade (CTS) - complexas e marcadas por contradições e conflitos, refletindo o 'clima' em que o trabalho científico é desenvolvido - distancia o processo educativo em ciências de uma efetiva alfabetização científica. 
Em consonância, entendemos que este quadro tem sido agravado pela descontinuidade (e alguns aspectos de cunho político-econômico) das diversas políticas públicas adotadas para o ensino formal que reforçam o paradigma positivista no ambiente escolar (e nos cursos de formação docente), além de, muitas vezes, desestimular os educadores, contrariando os diversos estudos acadêmicos que há muito tempo postulam ser imprescindível que o processo de ensino-aprendizagem seja atrativo, prazeroso, questionador, em um contexto dinâmico e voltado para a realidade dos alunos, percebendo-os como um ser social, crítico, interativo e que atua na sociedade, um agente de mudança, como sugerido por Freire (2001) e Vygotsky (1988).

Com este entendimento, Damásio e Peduzzi (2018), ao analisarem e discutirem o pensamento de Feyerabend sobre sua visão quanto à educação científica e a relação intrínseca que muitos estudiosos fazem entre ciência e razão (associando o modo de pensar de um racionalista a de um religioso fundamentalista), visualizaram uma afinidade dessa visão do autor com a realidade do ambiente escolar, onde a imagem estereotipada de que os cientistas são diferentes e buscam uma verdade absoluta está presente, levando-os a uma não identificação com o empreendimento científico e afastando-os do gosto e da prática da ciência, que seria privilégio apenas de pessoas "especiais". Damásio e Peduzzi (2018) ainda colocam que a desconstrução desta imagem estereotipada de ciência, inserindo sua pluralidade e humanidade, pode atrair os alunos para o empreendimento científico, fazendo com que sua predisposição em aprender seja despertada, estimulada, o que para nós justifica a busca por uma alfabetização científica com significado e que almeje um processo de ensino-aprendizagem contextualizado e crítico.
Neste sentido, além de uma constante busca de novas abordagens para o ensino de ciências, Viecheneski, Lorenzetti e Carletto (2012) apontam a importância de os docentes refletirem sobre as concepções que possuem sobre a educação e sobre a ciência e a tecnologia e sua influência na sociedade e no ambiente, concordando assim com Krasilchick (1987) no que concerne à presença das relações CTS para que a alfabetização científica possa emergir como uma alternativa viável à formação de todos os cidadãos.

A saber, Lorenzetti (2000) entende a alfabetização científica como um processo onde as diferentes linguagens das Ciências Naturais ganham significados para o indivíduo, levando-o a ampliar seu universo de conhecimento e sua cultura enquanto cidadão inserido e atuante na sociedade. Chassot (2003) e Fabri (2012), por sua vez, afirmam que ela se concretizará quando o ensino de ciências - das séries iniciais à graduação - favorecer a compreensão de conhecimentos, procedimentos e valores, preparando o educando para sua convivência com o avanço científico e tecnológico, viabilizando as aplicações da ciência no cotidiano para a melhora da qualidade de vida e ainda refletindo sobre suas implicações e impactos, suas limitações e as consequências negativas de seu desenvolvimento, transformando os saberes do senso comum em conhecimentos mais elaborados. Destarte, de acordo com Chassot (2006), o indivíduo alfabetizado cientificamente consegue apropriar-se da linguagem científica para interagir no mundo em que vive e tomar decisões que envolvem sua vida, a vida dos outros e do ambiente balizadas com escolhas conscientes e responsáveis frente às situações que surgirem.

Em face ao cenário descrito, é preciso abordar e alertar sobre a qualidade da formação docente, diretamente vinculada à prática 
da sala de aula e à qualidade do ensino (Fabri, 2012), visto que várias pesquisas indicam falhas em sua formação inicial, destacando o enfoque ainda positivista em muitos cursos de formação, onde o caráter disciplinar e fragmentado predomina e a relação entre a formação pedagógica e a formação específica é pouco equilibrada, prevalecendo aspectos teóricos que fundamentam as teorias de ensino e discutindo de maneira incipiente 'o que' e 'como' ensinar, e onde as disciplinas específicas não dialogam com as disciplinas pedagógicas, distanciando os futuros educadores da vivência interdisciplinar (Echeverría, Belisário, 2008; Gatti, 2010; Kist, Ferraz, 2010; Pereira, Fontoura, 2015b). Carvalho e Gil-Pérez (2006) acrescentam ainda a existência de uma carência de conhecimento da matéria, transformando o docente em um mero transmissor dos conteúdos do livro didático ou de apostilas, além da pouca proximidade dos docentes com as contribuições da pesquisa e as inovações científicas e didáticas.

No que tange ao cenário descrito, em algumas de nossas pesquisas realizadas no lócus das escolas (Pereira, 2008, 2015, Pereira, e Ferrão-filho, 2017, Pereira e Fontoura, 2015c e 2017, Pereira, Pedrini e Fontoura, 2019a), observamos no discurso dos docentes o questionamento em relação à sua formação profissional, onde a vivência da prática docente e a discussão dos temas científicos relacionando-os com os aspectos culturais, políticos e socioambientais não ocorreu de forma sistematizada e frequente, assim como a abordagem interdisciplinar. Tais questionamentos foram acrescidos de relatos que expuseram uma série de dificuldades vivenciadas pelos sujeitos relacionadas a esta carência oriunda de sua formação inicial, principalmente para aqueles com menos tempo de magistério, como o não aprofundamento e/ou a não abor- dagem de determinados temas, a dificuldade de relacionar alguns conceitos/fatos científicos com a vida cotidiana e questões socioambientais, a falta de segurança em desenvolver atividades que não tenham como base o livro didático ou a apostila e de realizar atividades mais lúdicas, que envolvam práticas e experimentos, a insegurança em propor e conduzir projetos interdisciplinares.

Outro aspecto que precisa ser mencionado é a formação continuada e permanente dos docentes que, segundo Souza e Chapani (2015), pode contribuir para a redução da lacuna existente entre os conhecimentos e competências adquiridos na formação inicial e a prática docente, a realidade escolar, tendo em vista que problematizando questões conceituais, metodológicas e epistemológicas, trabalha com o conhecimento prático profissional dos docentes. É oportuno destacar que, em nossos estudos, ela também foi alvo de questionamentos e discussões, pois, de acordo com os professores, nem todos que atuam nas redes de ensino têm oportunidade de uma formação continuada, principalmente em função de sua extensa jornada de trabalho e o acúmulo de atividades, algumas delas, nas palavras dos participantes, que extrapolam a função de professor (Pereira, 2015, Pereira, e Ferrão-filho, 2017, Pereira e Fontoura, 2015c e 2017, Pereira, Pedrini e Fontoura, 2019a).

Neste momento, chamamos a atenção para a importância do ensino dentro da ótica interdisciplinar para a efetivação da alfabetização científica, alicerçado na história da ciência, numa visão externalista de ciência e potenciado pelo movimento CTS (Costa, Monteiro, Costa, 2009, Moura et al., 2017). Com efeito, Fourez (2003) defende a abordagem interdisciplinar no ensino ao reconhecer que, por ser construída mediante representações ligadas a um contexto e a uma 
finalidade, não há espaço para uma verdade global nas ciências, mas para uma multiplicidade de concepções e modelizações possíveis da mesma situação concreta retratada, pois, "na prática, é raro que baste uma só disciplina" (p. 122).

A interdisciplinaridade é também preconizada pelos Parâmetros Curriculares Nacionais (PCNs) no que tange ao ensino de Ciências que almeja a alfabetização científica (Brasil, 1998), ainda ressaltando que os variados valores humanos não são alheios ao aprendizado científico e que a ciência precisa ser discutida em suas relações com a tecnologia e com as demais questões socioambientais desde a Educação Infantil, pois os temas de natureza científica e técnica possibilitam diferentes formas de expressão, não se tratando exclusivamente de ensinar a ler e escrever para que a criança possa aprender Ciências, mas usar o aprendizado em Ciências para que ela aprenda a ler e escrever (Brasil, 1997). Conforme suas indicações, as ciências precisam levar os discentes a se perceberem integrantes, dependentes e agentes transformadores do ambiente, identificando seus elementos e suas interações e auxiliando para a sua melhoria; para tal, faz-se necessária uma alfabetização científica que possibilite ao indivíduo conhecer as causas que geram os seus problemas e, assim, tomar decisão conscientemente (Praia, Gil-Peréz, Vilches, 2007).

Para Viecheneski, Lorenzetti e Carletto (2012), iniciando-se a alfabetização científica desde os anos iniciais, pode-se favorecer a elaboração e o aprimoramento na criança dos primeiros significados sobre o mundo, ampliando seus conhecimentos, sua cultura e a possibilidade de ela entender e participar ativamente na sociedade. Segundo os autores, o desenvolvimento dessa proposta demanda o desvelamento e a discussão da ciência, da tecnologia e da sociedade, englobando as inter-relações entre elas e entre elas e os aspectos históricos, sociais, econômicos e culturais.

Perante as premissas expressas, o professor tem o importante papel de produzir e apresentar situações que incentivem os alunos ao gosto pelo estudo das Ciências, o que acontecerá mais facilmente caso ele tenha conhecimentos básicos da área e de sua história e seus pressupostos, facilitando a condução do ensino de Ciências a partir de atividades problematizadoras, com temáticas capazes de relacionar e conciliar as diferentes áreas e esferas da vida cotidiana, ambicionando olhar para as ciências e seus produtos como elementos presentes no cotidiano (Sasseron, Carvalho, 2011). Desta forma, é essencial o professor ter consciência de suas convicções epistemológicas, visto que todo professor de Ciências atua também como um professor de filosofia da ciência, estando ele consciente ou não disso (Arthury, 2010). Neste sentido, Morin $(2002,2003)$ alerta para a necessidade de termos em mente tanto os efeitos negativos da compartimentação dos saberes e da incapacidade de articulá-los quanto a aptidão para contextualizar e integrar como uma qualidade fundamental da mente humana, precisando, desta forma, ser constantemente desafiada, e não atrofiada.

De acordo com Delizoicov, Slondo e Hoffmann (2011), estudos focados nas concepções epistemológicas dos docentes de Ciências indicam que muitos deles ainda detêm uma concepção empirista/indutivista em relação à produção do conhecimento científico, o que, conforme Gil-Perez et al. (2001), pode ser decorrente de uma percepção elitista, descontextualizada e socialmente neutra da ciência e de uma concepção aproblemática, a-histórica, cumulativa e de crescimento linear do saber científico. 
Cabe frisar que as Diretrizes Curriculares para os cursos relacionados à área de Ciências incluem competências e habilidades inerentes, tanto ao bacharel quanto ao licenciado, relacionadas ao entendimento histórico de produção do conhecimento referente a conceitos, princípios e teorias, assim como às relações entre Ciência, tecnologia e sociedade (BRASIL, 2001). Contudo, Mathews (1995) ressalta que, conforme os temas sobre História e Filosofia da Ciência são validados para a formação de docentes nas áreas científicas e regulamentados através por diretrizes curriculares, se faz necessário interrogarmo-nos sobre que tipos de cursos são realmente apropriados, pois muitas vezes seus estudantes são encaminhados aos departamentos de Filosofia, que programam textos de filósofos ou pensadores de outras áreas sem fazer a relação devida com a Ciência que estudam, lendo pouco ou nenhum texto referente aos grandes cientistas da área de Ciências.

\section{Sobre PRoCessos formativos de PROFESSORES de CiênCIAS}

A formação de professores para ensinar Ciências no Brasil tem merecido destaque em pesquisas nos cursos de pós-graduação (Krasilchik, Silva, Silva, 2015), na constituição de grupos de pesquisas em universidades, como também pelo número crescente de obras e trabalhos publicados em revistas e periódicos (Azevedo, 2008, Delizoicov, Slongo, 2011, Goldschmidt, 2012). Contudo, ainda existem lacunas a serem preenchidas especialmente quando relacionadas à formação docente inicial e continuada.

Reconhecemos que o ensino de Ciências enfrenta hoje desafios e dilemas; no entanto, entendemos que tais questões se relacionam à própria área da formação docente, que é convocada a repensar seus modelos formativos a partir das novas exigências sociais. Ampliou-se a diversidade de questões derivadas, sobretudo, da desresponsabilização dos estados e municípios para com a educação. Professores passaram a atuar em situações mais complexas, englobando desde escolas sem infraestrutura, salas lotadas e ambientes que não favorecem o ensino nem a aprendizagem, superando ações de caráter pedagógico.
Tomando a realidade escolar com toda a sua complexidade e a importância de compreendê-la com suas múltiplas dimensões, Bizzo (2012) aponta a necessidade de conhecermos a escola a partir da valorização dos saberes, das ações e das representações docentes que são tecidas no cotidiano, para assim acessarmos os ruídos, os incômodos do espaço e tempo escolares, como também sinalizar os atalhos percorridos com sucesso.

André (2013), reforçando a importância de conhecermos a escola mais de perto para promovermos dinâmicas formativas coerentes com as necessidades docentes, frisa que precisamos ouvir os professores, entendendo o que dizem, pensam, sentem e fazem, para assim descobrirmos com eles "quais os caminhos mais efetivos para alcançar um ensino de qualidade que se reverta numa aprendizagem significativa para todos os alunos" (p. 36). Assim, torna-se necessário possibilitar aos docentes a compreensão da configuração do contexto escolar, ou seja, levá-los a pensarem sobre o porquê de as coisas estarem como estão e ao mesmo tempo perceberem que podem imprimir sua 
marca, intervindo qualitativamente para o sucesso dos alunos.

Assumimos que nossas ações não se dão na neutralidade e por isso precisamos ter consciência de nossas decisões e posições, alterando quando necessário, buscando outras maneiras de olhar e valorizar o dia a dia da escola. Defendemos a necessidade de processos formativos que levem o professor a implicar-se em sua própria formação, assegurando uma base reflexiva para sua atuação profissional.

$\mathrm{Na}$ sociedade atual, o saber científico e tecnológico se faz presente nas atividades cotidianas de todos os indivíduos, influenciando nos modos de vida e na participação social. Logo, entendemos que aprender Ciências, hoje, possibilita alicerçar a base de saberes dos estudantes, conscientizando-os de suas responsabilidades, levando-os a participarem de modo mais informado, isto é, reconhecendo que suas ações podem afetar o todo. Neste sentido, entendemos que inserir e discutir temas sobre História e Filosofia da Ciência nas licenciaturas permite dar significados aos conteúdos científicos abordados de forma contextualizada e crítica, constituindo-se, segundo Martins (2007), em uma necessidade formativa dos futuros docentes, pois lhes propicia subsídios para a realização de atividades e estratégias didático-pedagógicas facilitadoras à intervenção docente e à compreensão dos conteúdos pelos discentes. No entanto, é oportuno defender que esta inserção precisa ser bem mais do que uma disciplina conteudista, e sim constituir-se em um espaço de debates sobre o papel da comunidade científica na sociedade e do processo de produção, divulgação e consumo do saber científico e tecnológico ao longo da história; do papel da mulher no desenvolvimento das Ciências; da importância da História da Ciência e das estratégias e metodologias de abordagem dos temas científicos no ensino das Ciências na Educação Básica e também um espaço que favoreça a interdisciplinaridade e a elaboração de projetos didático-pedagógicos.

Krasilchik, Silva e Silva (2015) ressaltam a imprescindibilidade da articulação entre Ciência e Sociedade, no sentido de explorar, no contexto escolar, a vida diária dos alunos com suas experiências, proporcionando novas compreensões sobre os problemas sociais e as relações destes com o mundo. Completam que a exclusão social e a luta pelos direitos humanos não podem ficar à margem dos currículos e, no momento, assumem uma importância cada vez mais evidente. Nesta perspectiva, inferimos que a aprendizagem em Ciências não deve reduzir-se à transmissão de conteúdos, mas possibilitar, a partir do conhecimento dos conteúdos, o desenvolvimento de atitudes científicas, auxiliando os alunos a reconhecerem seu papel social como participantes de decisões nas esferas individuais e coletivas.

A literatura sobre formação docente tem sinalizado, há alguns anos, a necessidade de buscarmos dinâmicas formativas que favoreçam o processo de ensino aprendizagem dos alunos, em qualquer nível de escolaridade ou componente curricular. André (2013) reforça que temos muito que conhecer em como formar professores para atuar no mundo atual marcado pela complexidade que entrecruza educação e sociedade e por consequência, a própria profissão.

Compreendemos que a escola hoje recebe múltiplas influências, seja das novas tecnologias, da mídia, da própria globalização e ainda o fato de que esta instituição não é mais a detentora do saber, uma vez que as informações e os conhecimentos chegam de 
todos os lados. A sociedade convoca a escola a rever seu papel, contudo vale ressaltar que o próprio seio social se encontra cada vez mais marcado pela desigualdade, subordinação e exclusão.

Diante dessas situações, evidencia-se a necessidade de buscarmos caminhos outros para formação docente, onde conhecimentos sejam explorados, possibilitando (re)conhecer fatores que favoreçam aprendizagens e reaprendizagens profissionais. Assim, é necessário suscitar novos conceitos e metodologias nas capacitações dos professores, para que se tornem atuantes e críticos ante situações socioambientais e possam influenciar de forma efetiva nas mudanças de atitudes dos discentes (Cuba, 2010). No entanto, nesse movimento de buscas, não podemos esquecer que o professor não é o único sujeito responsável pela melhoria do ensino-aprendizagem, pois há outros fatores que concorrem para uma educação de qualidade, tais como recursos disponíveis nas escolas, uma organização do trabalho escolar que proporcione suporte físico, pedagógico e emocional aos docentes, salários dignos, condições de trabalho adequadas, e carreira atrativa, um conjunto de condições que deve fazer parte de uma política geral de apoio aos docentes (André, 2013).

Neste sentido, os desafios enfrentados pelos professores no ensino de Ciências não se concentram apenas no próprio componente curricular, mas são influenciadas por questões em nível macro, que em muito extrapolam sua formação. Desta forma, as propostas de formação precisam abordar as problemáticas socioambientais integrando-as com reflexões sobre a escola, na escola e para a escola, desfazendo certezas e clarificando percepções, semelhante ao processo de alfabetização científica desejado para os discentes.
Pensar o cotidiano docente conjugadamente com os profissionais que o vivem e tecem é, em nosso entendimento, traçar um caminho epistemológico aonde vamos descobrindo coletivamente outras formações que são produzidas no dia a dia das escolas e das salas de aulas. Nesse processo de descoberta, vamos ecoando práticas potentes que são silenciadas pela perspectiva da racionalidade técnica e do positivismo que veem professores como simples executores. Com Gatti (2013) vemos que esse silenciamento se faz na ausência do professor como sujeito em muitos estudos da área da formação docente. Para a autora, a concretude dos atores e fatores presentes na situação escolar nem sempre é trazida à luz, tratando-se, por exemplo, o professor como vaga abstração, um ser universal despessoalizado e descontextualizado. Diante disso, a autora pontua a necessidade de construção de uma área de conhecimento sobre modos possíveis de trabalhar a educação das novas gerações implicada numa intensa relação entre pensamento e as ações concretas situadas nas salas de aula.

Nóvoa (2017) nos convoca a construir outro lugar para a formação de professores, numa dimensão que consolide a posição de cada pessoa como profissional e a própria posição da profissão. Essa convocação parte de seu reconhecimento do atual momento marcado pelo sentimento de insatisfação e por políticas de desprofissionalização a partir das lógicas de burocratização, privatização e controle. Em face desta situação, o autor salienta que precisamos recuperar a ligação com as escolas e os educadores no sentido de superar a distância entre as ambições teóricas e a realidade concreta das escolas e dos professores.

O lugar a que Nóvoa (2017) se refere deve ser um espaço de encontro e de junção 
das várias realidades que configuram o campo docente, "não só no plano da formação, mas também no plano de sua afirmação e reconhecimento" (p. 1115). Partindo dessa explicitação, entendemos que a evidenciação das teses docentes (Figueira, 2019), pode constituir-se numa ambiência promotora da construção de conhecimentos no contexto escolar assim como da legitimação do professor enquanto autor e sujeito de sua ação.

Em busca deste lugar, que coloque os professores e a escola da educação básica numa posição legítima de potência formativa e de produção de conhecimentos, elaboramos o presente texto como forma de compartilhar o pensar a prática pedagógica com o outro a partir do entrecruzamento de olhares. Entendemos que a reinvenção das práticas pelos professores não emerge do vazio, mas advém de seu conhecimento apropriado nas trajetórias de formação, sendo potencializada na/pela relação com os estudantes. Logo, este processo possibilita a fundamentação das escolhas e dos devires pedagógicos, pois os docentes com suas concepções mobilizam conhecimentos para compreender situações e inferir/criar novos modos de atuação educacional (Gatti, 2013).

Nóvoa (2017) corrobora com Gatti (2013) ampliando nossa visão quanto à autoria docente nos processos de decisão em sala de aula, pois para ele os melhores professores são capazes de criar condições para que os alunos trabalhem o conhecimento. A sua principal responsabilidade não é dar 'boas aulas', mas organizar as atividades diárias de tal forma que os alunos aprendam, façam a sua viagem pela cultura e pela ciência.

Ante ao exposto, a questão que se coloca centra-se nos desafios que o conhecimento elaborado no cotidiano escolar oferece. Para Nóvoa (2017), um dos pilares centrais da escola é o conhecimento, sendo este "indissociável de lógicas pessoais e colegiais, de um conhecimento que reside também na experiência e nas 'comunidades profissionais' que o produzem e difundem"' (p.1121).

Com os autores acima, podemos assumir que praticar a docência se constitui em um ato criador, transformador e reflexivo da experiência e com a experiência, processo permanente de aprendizagem, de entrecruzamentos teóricos e de tessitura de outras possibilidades de ensino e formação; assim, apostamos no conceito de alfabetização científica como recurso para alimentarmos processos formativos mais alicerçados em aportes consistentes, já que a escola, como a temos hoje, não tem conseguido acompanhar tais transformações socioculturais e técnico-científicas, nem abordá-las ou discuti-las em profundidade.

\section{DESAFIOS E PERSPECTIVAS: TECENDO ARTICUlaÇões}

A alfabetização científica pretende tornar o cidadão capaz de dialogar e argumentar com outros indivíduos, conduzir a relação entre saber-fazer e poder-fazer e enfrentar diferentes situações concretas de maneira racional usando os saberes das ciências. Com esta perspectiva, conforme já colocado neste artigo, é essencial o ensino interdisciplinar, a abordagem CTS e a inserção de questionamentos, temáticas e problemas cotidianos de cunho socioambiental e cultural, mediante múltiplas práticas, onde controvérsias e debates têm papel importante no desenvolvimento do educando (Carvalho, 2007). 
Mas, tendo como base os pressupostos da alfabetização científica, qual seriam os objetivos e o papel do professor em sala de aula?

Lemke responde dizendo que os docentes devem fazer com que os alunos sejam capazes de raciocinar e usar ferramentas e práticas científicas para a resolução de problemas, além de compreender os fenômenos naturais e tecnológicos. Vamos um pouco mais além, em sintonia com Freire (1980, 2002), Chassot (2000, 2003), Krasilchik e Marandino (2004), Carvalho (2007) e Trivelato (2011), entendendo que o trabalho docente deve orientar os alunos para que, muito mais que a capacidade de 'ler a ciência', eles consigam discuti-la e opinar sobre ela, fazendo parte de sua cultura e, assim, poder 'ler o mundo' em que vivem e atuar no controle e previsão de suas transformações, visando a melhoria da qualidade de vida socioambiental e a inclusão social consciente, crítica e emancipatória.

Diante deste panorama, Sasseron e Carvalho (2008), em um trabalho que discute a alfabetização científica com diversos autores, identificam três pontos comuns no discurso desses pesquisadores, denominados de 'Eixos Estruturantes da Alfabetização Científica', que apoiam a idealização, o planejamento e análise de propostas de ensino que a desejam. São eles: 1. compreensão básica de termos, conhecimentos e conceitos científicos fundamentais - para a compreensão de informações e situações do dia a dia; 2. compreensão da natureza da ciência e dos fatores éticos e políticos que circundam sua prática - para lidar com novas circunstâncias, analisando-as de maneira contextualizada e reflexiva; 3. entendimento das relações existentes entre ciência, tecnologia, sociedade e meio-ambiente - reconhecendo que quase todo fato da vida é influenciado pelas ciências e tecnologias.

Nesta linha de pensamento, Milaré e Alves Filho (2010) apresentam as capacidades ou objetivos operacionais postulados por Fourez, no livro Alfabetización Científica y Tecnológica (1997). São elas: 1. o bom uso de especialistas - gerando autonomia e capacidade de reconhecimento de boas práticas desses profissionais; 2 . capacidade de fazer bom uso de caixas-pretas (entendidas como 'o desconhecido') - sendo capaz de se aprofundar em determinado conhecimento para resolver problemas; 3 . saber utilizar modelos simples, essencial na formação do pensamento científico, evitando sistemas complexos; 4. utilizar e criar modelos interdisciplinares, enfrentando situações e usando-os como consulta a especialistas, observações, saberes de diversas áreas e do cotidiano; 5. compreender e usar corretamente metáforas, analogias e comparações presentes na cultura científica como formas de expressão; 6 . fazer bom uso das traduções, interpretando o significado de algo em diferentes momentos e agindo sobre um problema em contextos diversos; 7. saber usar a negociação e a articulação entre saberes e decisões - capacidade de argumentar, negociar e usar os saberes na defesa de seu posicionamento; 8. fazer bom uso de aspectos técnicos, éticos e políticos - dependendo da necessidade imposta pelas situações em que vive.

A partir destas premissas, ao nos debruçarmos sobre a prática pedagógica voltada para a alfabetização científica, nos deparamos com habilidades e percursos propostos por diversos autores, muitos com aspectos convergentes. Carvalho (2007) destaca três habilidades essenciais na ação docente: saber estimular a argumentação em sala de aula; capacidade de transformar a linguagem do senso comum (e do aluno) em linguagem científica de maneira sutil e cautelosa para 
não tolher as manifestações dos discentes; saber introduzir os alunos nas linguagens matemáticas, o que é tido como a mais complexa.

Frente a estas proposições, julgamos ser imperiosa uma atuação docente contextualizada à realidade sociocultural do aluno, inserindo aspectos da história das Ciências, os mecanismos relacionados à sua construção, dentro dos enfoques CTS e interdisciplinar, sempre buscando criticidade e aprendizagem prazerosa e com significado. Deste modo, o uso de recursos audiovisuais, textos de diferentes estilos (para além do livro didático), atividades lúdicas, projetos (de preferência envolvendo outras disciplinas), debates/discussões, aliados à apropriação da argumentação e do ensino por investigação como estratégia, seriam alguns exemplos de abordagens didáticas que poderiam contribuir para a ação pedagógica que busca a alfabetização científica. Com este entendimento, temos trabalhado junto aos professores da Educação Básica alguns projetos que discutem a prática docente no ensino de Ciências e as perspectivas lúdica e interdisciplinar, visando a alfabetização científica, dentro de um contexto de pesquisa ação e formação continuada. Alguns destes projetos foram realizados no lócus da escola, uns envolvendo professores das diversas áreas de ensino outros apenas docentes do $1^{\circ}$ segmento do Ensino Fundamental; todos propondo e desenvolvendo com os sujeitos atividades/estratégias lúdicas envolvendo dinâmicas de grupo, histórias em quadrinhos, desenhos, jogo de palavras, aulas-passeio, produção de textos (Pereira, 2015, Pereira, e Fontoura, 2015a e 2016, Figueira e Fontoura, 2016, Pereira, Pedrini, e Fontoura, 2019a e 2019b, Pereira, e Ferrão-Filho, 2019).

Vale a pena reforçar que, em relação ao enfoque interdisciplinar e ao enfoque CTS, percebemos nas premissas já apresentadas uma grande dificuldade entre os profissionais de ensino, não apenas para colocá-los em prática, mas também para entendê-los e valorizá-los, pois não fizeram parte da trajetória dos docentes ao longo de sua formação básica, o que indica a necessidade da inclusão destes enfoques e de uma maior e mais intensa discussão e experimentação dos mesmos nos cursos de formação docente de todos os níveis. Conforme Carvalho (2007), a mudança de enfoque no ensino será uma realidade somente se o papel e a prática do professor em sala de aula forem modificados, com novos discursos e habilidades além das tradicionais.

Quanto aos recursos audiovisuais, destacamos que eles compõem a cultura científica, sendo elaborados, segundo Chernicharo, (2010), tanto para a produção de modelos/ recursos explicativos do mundo natural que não pode ser visto ou estudado em sua totalidade quanto para a divulgação científica. A autora ressalta, contudo que, apesar de as imagens fazerem parte de nosso cotidiano, nos relacionamos com elas normalmente de forma automática, sem observá-las atentamente. No entanto, a autora lembra que, ao considerarmos a realidade das redes de ensino brasileiras, a maioria das escolas não possui os recursos necessários para apresentar os muitos aspectos da Ciência e, desta forma, o professor precisa fazer uso de desenhos esquemáticos, imagens e ilustrações de livros didáticos e apostilas, vídeos, animações. Ressaltamos que a linguagem visual é importante porque amplia a capacidade cognitiva e interpretativa dos alunos, auxiliando no processo de ensino-aprendizagem. Com efeito, Arroio e Giordan (2006) afirmam que a linguagem audiovisual consegue dizer bem mais do que percebemos na linguagem escrita, pois ocorre através de vários cami- 
nhos simultaneamente sem que percebamos, repercutindo com imagens básicas, simbólicas, centrais com as quais nos identificamos ou relacionamos. Sob esta ótica, temos como exemplo o potencial das histórias em quadrinhos (comerciais ou criadas especificamente para trabalhar dado conteúdo, usadas apenas para leitura e discussão ou a criação de quadrinhos pelos próprios alunos), utilizadas, estudadas e reconhecidas pelos autores (Pereira, 2008, 2015 e 2018, Pereira, e Fontoura, 2015d e 2016, Pereira, e Santos, 2013, Santos, e Pereira, 2013 e 2016) e por diversos pesquisadores da área de Ensino de Ciências.

No que tange à ludicidade, Conceição Lopes (2004) a define como um conjunto de processos dinâmicos inter-relacionados protagonizados pela humanidade que conferem uma significação lúdica aos seus comportamentos, sendo compreendida como um fenômeno inerente à natureza de nossa espécie, partilhado por todas as faixas etárias ao longo da vida do indivíduo. Neste sentido, gera satisfação, funcionalidade e espontaneidade e estimula a imaginação, a criatividade, a abstração, a integração dos conhecimentos adquiridos e a criticidade, facilitando a aprendizagem, a aproximação e interação entre os grupos, a canalização da energia dos alunos, a capacidade de explorar as ideias e o mundo, a conscientização de seus próprios sentimentos, todos estes aspectos positivos aos processos de desenvolvimento psicossocial e intelectual sendo o seu uso oportuno e desejável na prática docente (Freitas, Aguiar, 2012; Modesto, Rubio, 2014; Pereira, Fontoura, 2016).

Finalizando, cabe evocar a importância da argumentação e do ensino por investigação como abordagem didática na alfabetização científica, visto que ambos são aspectos do fazer científico, sendo elementos da cul- tura científica cuja linguagem é argumentativa. Para Sasseron (2015), tais abordagens se processam através de uma situação-problema, na qual os alunos têm papel ativo na construção do conhecimento, precisando se engajar para solucioná-lo, o que promove liberdade e autonomia intelectuais. A autora entende a argumentação como a base de pensamento, vinculada aos processos de análise de problemas, dados, anomalias e conflitos, sendo as interações discursivas promotoras e estimuladoras deste processo, permitindo, assim, romper com a cultura escolar pautada, hegemonicamente em práticas didáticas descontextualizadas com o campo de conhecimento da disciplina. Em acordo a esta linha de pensamento, entendemos a argumentação como fator preponderante no processo de alfabetização científica visto que ela estimula, intensifica e viabiliza os questionamentos dos processos e do saber científico estabelecido, dá voz aos discentes e aos seus saberes, propicia trocas e (re)construção do conhecimento.

Pensar a formação de professores em nosso país articulada com a alfabetização científica tem se configurado um desafio para nós pesquisadores devido principalmente aos ataques sofridos no campo científico pelo contexto de negacionismo e de questionamento da Ciência e de seus produtos. Tomando nossas produções acadêmicas como forma de enfrentamento, destacamos que a construção de conhecimentos sobre a docência em Ciências precisa englobar o professor e sua experiência articulando as dimensões individuais e coletivas enquanto modo de instrumentalização frente às questões impostas pela sociedade bem como as que surgem no interior das escolas. Assumimos que conhecer produz um mundo no qual os sujeitos dele participantes tornam-se capazes de refletir sobre suas realizações, 
operando efetivamente transformações nos seus domínios existenciais.

Reforçando nosso entendimento, Krasilchik e Marandino (2004) explicam que há uma dupla preocupação da escola com relação ao ensino de Ciências, a que toma a perspectiva acadêmica voltada para conteúdos e conceitos, e outra mais utilitária, centrada na formação do cidadão que compreende os conceitos e os utiliza para enfrentar desafios e para refletir sobre o seu cotidiano. Assim, um ensino de Ciências pautado por diálogos entre alunos e professor e entre os próprios alunos poderá encaminhar apreensões sobre o papel que a Ciência tem nas suas vidas, na perspectiva de uma busca racional e crítica de dados empíricos desencadeados na práxis do viver, servindo de base e orientação para suas decisões pessoais e sociais. Apostamos na implicação dialógica e integrada no ensino de Ciências centrando suas proposições na promoção de práticas que

\section{Nota}

1. Fhttps://unesdoc.unesco.org/ark:/48223/pf0000102819

\section{REFERÊNCIAS}

André, M. (2013) O que é um estudo de caso qualitativo em Educação? Revista FAEEBA, Salvador, v.22, n.40, p. 95-103.

Arroio, A., e Giordan, M. (2006). O vídeo educativo: aspecto da organização do ensino. Química Nova na Escola, São Paulo, 24.

Arthury, L. H. M. (2010). A cosmologia moderna à luz dos elementos da epistemologia de Lakatos. Dissertação de Mestrado, Universidade Federal de Santa Catarina. Florianópolis, SC, Brasil.

Auler, D., e Delizoicov, D. (2001). Alfabetização científico-tecnológica para quê? Rev. Ensaio, Belo Horizonte, 3(2), p.122-134.

Azevedo, R. O. M. (2008). Ensino de ciências e formação de professores: diagnóstico, análise e proposta. Dissertação de mestrado. Universidade do Estado do Amazonas. 
Bizzo, N. M. V. (2012) Pensamento científico: a natureza da ciência no ensino fundamental. São Paulo: Editora Melhoramentos.

Brandi, A. T. E., Gurgel, C. M. A. (2002). A Alfabetização Científica e o Processo de Ler e Escrever em Séries Iniciais: Emergências de um Estudo de Investigação-Ação. Ciência \& Educação, 8(1), 113-125.

Brasil. (1997). Secretaria de Educação Fundamental. Parâmetros curriculares nacionais: ciências naturais. Brasília: MEC/SEF.

. Secretaria de Educação Fundamental. (1998). Parâmetros Curriculares Nacionais: terceiro e quarto ciclos do ensino fundamental; Ciências. Brasília: MEC/SEF, v. 4.

. Ministério da Educação. (2001). Diretrizes Curriculares para os cursos de Ciências Biológicas. CNE. Parecer CNE/CES 1.301/2001, Diário Oficial da União de 7/12/2001, Seção 1, p. 25. Disponível em http://portal.mec.gov.br/cne/arquivos/pdf/CES1301.pdf. Acesso em março 2013.

Ministério da Educação. Base Nacional Comum Curricular. Brasília: Ministério da Educação, 2018. Disponível em http://basenacionalcomum.mec.gov.br/. Acesso em 21 outubro 2019.

Bydlowski, C. R., Lefévre, A. M. C., Pereira, M. I. T. (2011). Promoção da saúde e a formação cidadã: a percepção do professor sobre cidadania. Ciência e Saúde Coletiva, Rio de Janeiro, 16(3), 17711780.

Cachapuz, A., Gil-Perez, D., Carvalho, A. M. P., Praia, J., e Vilches, A. (2005). A necessária renovação do ensino de ciências. São Paulo: Cortez.

Carvalho, A. M. P. de. (2007). Habilidades de professores para promover a Enculturação Científica. Contexto \& Educação, 22(77), pp. 25-49.

Carvalho, A. M. P. de, e Gil-Pérez, D. (2006). Formação de professores de ciências: tendências e inovações $\left(8^{\text {a }}\right)$. São Paulo: Cortez.

Chassot, A. I. (2003). Alfabetização científica: uma possibilidade para a inclusão social. Revista Brasileira de Educação, 22, 89-100.

Chassot, A. I. (2006). Alfabetização Científica: questões e desafios para a educação (4ª). Ijuí: Ed. Unijuí.

Chernicharo, P. de S. L. (2010). Práticas docentes e cultura cientifica - O caso da Biologia. Dissertação de Mestrado, Faculdade de Educação, Universidade de São Paulo, São Paulo, SP, Brasil.

Chrispino, A. (2008). O enfoque CTS - Ciência, Tecnologia e Sociedade e seus impactos no ensino. Revista Tecnologia \& Cultura. Rio de Janeiro, 10(13), 7-17.

Costa, I. A. P. M. da C., Monteiro, M. J. P. F. G., e Costa, M. do R. P. de S. C. (2009). Interdisciplinaridade na Alfabetização Científica dos cidadãos: de uma exigência curricular a um imperativo profissional. Atas do Congresso Internacional Galego-Português de Psicopedagogia, Braga, PT, 10 .

Cuba, M. A. (2010). Educação ambiental nas escolas. ECCOM-Revista Educação, Cultura e Comunicação, 1(2), pp. 23-31. 
Cunha, R. B. (2017). Alfabetização científica ou letramento científico? Interesses envolvidos nas interpretações da noção de scientific literacy. Revista Brasileira de Educação, 22(68), 169-186.

Damasio, F., e Peduzzi, L. O. Q. (2018) Para que ensinar ciência no Século XXI? - Reflexões a partir da filosofia Feyerabend e do ensino subversivo para uma aprendizagem significativa crítica. Revista Ensaio, 20, 1-19.

Delizoicov, N. C., e Slongo, I. I. P. (2011). O ensino de Ciências nos anos iniciais do Ensino Fundamental: elementos para uma reflexão sobre a prática pedagógica. Série-Estudos. Campo Grande, MS, n.32, p.205-221.

Delizoicov, N. C., Slongo, I. I. P., e Hoffmann, M. B. (2011). História e Filosofia da Ciência e formação de professores.: a proposição dos cursos de licenciatura em Ciências Biológicas do Sul do Brasil. Anais do Seminário Internacional de Representações Sociais, Subjetividade e Educação - SIRSSE, Curitiba, PR, Brasil, 1.

Driver, R., Newton, P., e Osborne, J. (2000). Establishing the norms of scientific argumentation in classrooms. Science Education, 84(3), p. 287-312.

Echeverría, A. R., e Belisário, C. M. (2008). Formação inicial e continuada de professores num núcleo de pesquisa em ensino de ciências. Revista Brasileira de Pesquisa em Educação em Ciências, 8(3), s. p.

Fabri, F. (2012). O ensino de Ciências nos anos iniciais do ensino fundamental sob a ótica CTS: uma proposta de trabalho dos artefatos tecnológicos que norteiam o cotidiano dos alunos. Dissertação de Mestrado, Universidade Tecnológica Federal do Paraná, Ponta Grossa, Paraná, Brasil.

Figueira, S. T. S. e Fontoura. H. A. (2016) O ensino de ciências na Educação de Jovens e Adultos: reflexões sobre uma proposta pedagógica. Revista Acta Scientiae. , v.18, p.840 - 852.

Figueira, S. T. S. (2019). Teses docentes sobre o processo de ensinar e aprender Ciências. ACTIO, Curitiba, 4(1), p. 1-25.

Figueira, S. T. S., e Fontoura, H. A. (2018). Ensinar e aprender Ciências: o que dizem professores? Areté (Manaus), 11, p. 55-62.

Fourez, G. (2003). Crise no ensino de ciências? Investigações no ensino de ciências, 8(2), 109-123.

Freire, P. (1980). Educação como prática da liberdade, São Paulo: Paz e Terra.

Freire, P. (2001). Educação e participação comunitária. In: Política e educação - Coleção Questões da nossa época (5 ed). São Paulo: Cortez.

Freire, P. Pedagogia do oprimido. (2002). Rio de Janeiro: Paz e Terra.

Freire, P. (2005). A importância do ato de ler-em três artigos que se completam. São Paulo: Cortez.

Freitas, M. S. de, Aguiar, G. P. (2012). Educação e ludicidade na primeira fase do Ensino Fundamental. Interdisciplinar: Revista Eletrônica da Univar, 7,p. 21-25.

Fronza, K. R. K. (2016). Repercussões sociais decorrentes do avanço científico e tecnológico: manifestações curriculares resultantes da intervenção docente. Tese de Doutorado, Universidade Federal de Santa Catarina, Florianópolis, SC, Brasil. 
Gatti, B. A. (2010). A formação de professores no Brasil: características e problemas. Educação e Sociedade, 31(113), 1355-1379.

Gatti, B. A. (2013). A prática pedagógica como núcleo do processo de formação de professores. In: GATTI et al. Por uma política nacional de formação de professores. São Paulo: Editora Unesp, 1355-1379.

Gil Pérez, D., Montoro, I.F., Alís, J. C., Cachapuz, A., e Praia, J. (2001). Para uma imagem não deformada do trabalho científico. Ciência e Educação, 7(2), 125-153.

Goldschmidt, A. I. (2012). O ensino de Ciências nos anos iniciais: sinalizando possibilidades de mudanças. Tese de doutorado. Programa de Pós-Graduação em Educação em Ciências: Química da vida e saúde, Santa Maria, RS.

Grando, K. B. (2012). O letramento a partir de uma perspectiva teórica: origem do termo, conceituação e relações com a escolarização. Anais do Seminário de Pesquisa em Educação da Região Sul-ANPED Sul, Caxias do Sul, RS, Brasil, 9.

Kist, C. P., e Ferraz, D. F. (2010). Compreensão de professores de biologia sobre as interações entre ciência, tecnologia e sociedade. Revista Brasileira de Pesquisa em Educação em Ciências, 10(1), s.p.

Kleiman, A. B. (2008). Os estudos de letramento e a formação do professor de língua materna. Linguagem em (Dis)curso - LemD, 8(3), p. 487-517.

Krasilchick, M. (1987). O professor e o currículo das ciências. São Paulo: EDUSP.

Krasilchick, M. (2005). Práticas de ensino de Biologia (4 ed). São Paulo: EDUSP.

Krasilchick, M., e Marandino, M. (2004). Ensino de ciências e cidadania. São Paulo: Moderna, 2004

Krasilchik, M., Silva, R. L. F., e Silva, P. F. (2015). Perspectivas da educação em Ciências expressas nos periódicos Science e Nature. Ens. Pesqui. Educ. Ciên., Belo Horizonte, 17(1), p.192-207. Disponível em: <http://www.scielo.br/scielo.php?script=sci_arttext\&pid=S1983-2117201500010 0192\&lng=pt\&nrm=iso $>$. Acesso em set. 2019.

Lemke, J. L. (1998). Teaching all the languages of science: words, symbols, images, and actions. Disponível em: $<$ http://academic.brooklyn.cuny.edu/ education/jlemke/papers/barcelon.htm $>$. Acesso em 28 set. 2019.

Lorenzetti, L. (2000). Alfabetização cientifica no contexto das séries iniciais. Dissertação de Mestrado, Universidade Federal de Santa Catarina, Florianópolis, SC, Brasil.

Lorenzetti, L., e Delizoicov, D. (2001). Alfabetização científica no contexto das séries iniciais. Ensaio - Pesquisa em Educação em Ciências, 3(1), 37-50.

Mamede, M., e Zimmermann, E. (2007). Letramento Científico e CTS na Formação de Professores para o Ensino de Física. Anais do SNEF - Simpósio Nacional de Ensino de Física, São Luís, MA, Brasil, 16.

Martins, A. F. P. (2007). História e filosofia da ciência no ensino: há muitas pedras nesse caminho. Caderno Brasileiro de Ensino em Física, 24(1), p. 112-131. 
Mathews, M. R. (1995). História, filosofia e ensino de ciências: a tendência atual de reaproximação. Caderno Catarinense de Ensino de Física, 12(3), p. 164-214.

Milaré, T., e Alves Filho, J. de P. (2010). Ciências no nono ano do Ensino Fundamental: da disciplinaridade à alfabetização científica e tecnológica. Rev. Ensaio, 12(2), p.101-120.

Modesto, M. C., e Rubio, J. de A. S. (2014). A importância da ludicidade na construção do conhecimento. Revista Eletrônica Saberes da Educação, 5(1), s/p.

Morin, E. (2002). A cabeça-bem-feita: repensar a reforma, reformar o pensamento. Rio de Janeiro: Bertrand Brasil.

Morin, E. Da necessidade de um pensamento complexo. In: Martins, F. M., e Silva, J. M. (2003). Para navegar no século 21: tecnologias do imaginário e cibercultura. Porto Alegre: Sulina/Edipucrs, p. $13-36$.

Mortimer, E. F., e Machado, A. H. (1996). A Linguagem em uma Aula de Ciências. Presença Pedagógica, 2(11), p. 49-57.

Moura, W. A. L. de, Moura, M. S. L. A., Festucci, V. B. M., Bonzanini, T. K., Fernandez, F. da R. B. (2017, julho). Interdisciplinaridade e o ensino de ciências: o professor compreende essa relação?. Anais do Encontro Nacional de Pesquisa em Educação em Ciências - ENPEC, Florianópolis, $\mathrm{SC}$, Brasil, 11.

Nóvoa, A. (2017). Firmar a posição como professor, afirmar a profissão docente. Cadernos de Pesquisa, 47(166), p.1106-1133.

Pereira, E. G. C. (2008). Educação Ambiental na escola: Ações Pedagógicas no contexto Lixo-Água-Saúde. Dissertação de Mestrado, Instituto Oswaldo Cruz/FIOCRUZ, Rio de Janeiro, RJ, Brasil.

Pereira, E. G. C. (2015). Ações Pedagógicas para a Educação Ambiental: ampliando o espaço da ação docente. Tese de Doutorado, Instituto Oswaldo Cruz /FIOCRUZ, Rio de Janeiro, RJ, Brasil.

Pereira, E. G. C. (2018). Oficina de história em quadrinhos como recurso didático no ensino de ciências para crianças. Revista Tecné, Episteme y Didaxis, n. extraordinário, s. p.

Pereira, E. G. C., e Ferrão-Filho, A. da S. (2017). Ambiente aquático em questão: percepção de docentes dos anos iniciais do Ensino Fundamental. Revista Enseñanza de las Ciencias, n. extraordinário, pp. 5367-5372.

Pereira, E. G. C., e Ferrão-Filho, A. da S. (2019). Educar ambientalmente: percepções de docentes do 10 segmento do ensino fundamental. Anais do Encontro Nacional de Pesquisa em Educação em Ciências - ENPEC, Natal, RN, Brasil, 12.

Pereira, E. G. C., e Fontoura, H. A. da. (2013). Dinâmicas de grupo como recurso pedagógico no ensino de ciências. Enseñanza de las ciencias: revista de investigación y experiencias didácticas, no. Extra - IX Congreso de Investigación en Didáctica de las Ciencias, pp. 2737-2741. Disponível em: <https://www.raco.cat/index.php/Ensenanza/article/view/308050>.

Pereira, E. G. C., e Fontoura, H. A. da. (2015a). Educação Ambiental (EA) na perspectiva do ensino de ciências. Revista Interacções, 11(39), pp. 564-576.

Pereira, E. G. C., e Fontoura, H. A. da. (2015b). Educação Ambiental e o ensino de Ciências: discutindo a ação docente. In: C. Puggian, C. F. dos Santos, S. F. Raulino, C. R. da S. Machado (Orgs). 
IV Seminário de Justiça Ambiental, Igualdade Racial e Educação - Trabalhos completos. Duque de Caxias: Editora UNIGRANRIO, 2015, 102-118.

Pereira, E. G. C., e Fontoura, H. A. da. (2015c). Inserção da Educação Ambiental no ensino público - visão de duas equipes pedagógicas. In: Membiela, P., Casado, N., Cebreiros, M. I. (Eds.). Presente y Futuro de la Enseñanza de las Ciencias. Ourense: Educación Editora, 65-69.

Pereira, E. G. C., e Fontoura, H. A. da. (2016, maio/agosto). Percepções da dimensão ambiental no contexto lúdico: docentes enquanto sujeitos. Revista Ciências \& Ideias, 7(2), p.51-72.

Pereira, E. G. C., e Fontoura, H. A. da. (2017). Educação Ambiental na escola: percepções docentes. Anais do Encontro Nacional de Pesquisa em Educação em Ciências - ENPEC, Florianópilis, SC, Brasil, 11.

Pereira, E. G. C., Pedrini, A. de G., e Fontoura, H. A. da. (2019a). Contextualizando Aquecimento Global e suas consequências ludicamente: algumas percepções de docentes do ensino fundamental. Ensino, Saúde e Ambiente, 12 (2), pp. 186-211.

Pereira, E. G. C., Pedrini, A. de G., e Fontoura, H. A. da. (2019b). Discutir para criar, criar para (re) construir conhecimento - Aquecimento Global em uma perspectiva lúdica. Anais do Encontro Pesquisa em Educação Ambiental - EPEA, São Cristóvão, SE, Brasil, 10.

Pereira, E. G. C., e Santos, T. C. (2013). A utilização de Oficinas de Histórias em Quadrinhos em um processo avaliativo. Revista Práxis, 5(especial), pp. 43-47.

Pereira, E. G. C., e Santos, T. C. (2016). Construindo textos em ciências. Anais do Congresso Nacional de Educação - CONEDU, Natal, RN, Brasil, 3.

Praia, J., Gil-Pérez, D., e Vilches, A. (2007). O papel da natureza da ciência na educação para a cidadania. Ciência \& Educação, 13(2), p. 141-156.

Santos, T. C. dos, e Pereira, E. G. C. (2013). Oficinas de histórias em quadrinhos como recurso pedagógico no ensino de ciências. Revista Enseñanza de las Ciencias, n. extraordinário, pp.32003204.

Santos, W. L. P. (2007). Educação científica na perspectiva de letramento como prática social: funções, princípios e desafios. Revista Brasileira de Educação, 12(36), 474-550.

Santos, W. L. P., e Mortimer, E. F. (2001). Tomada de Decisão para Ação Social Responsável no Ensino de Ciências. Ciência \& Educação, 7(1), 95-111.

Sasseron, L. H. (2015, novembro). Alfabetização científica, ensino por investigação e argumentação: relações entre ciências da natureza e escola. Revista Ensaio, 17, n. especial, p. 49-67.

Sasseron, L. H., e Carvalho, A. M. P. de. (2011). Alfabetização Científica: uma revisão bibliográfica. Investigações em Ensino de Ciências, 16(1), pp. 59-77.

Soares, M. (2004). Alfabetização e Letramento: caminhos e descaminhos. Acervo Digital UNESP, pp. 96-100. Disponível em: < http://www.acervodigital.unesp.br/bitstream/123456789/40142/1/ 01d16t07.pdf $>$. Acesso em 30/10/2014

Souza, A. L. S., Chapani, D. T. (2015). Necessidades formativas dos professores que ensinam ciências nos anos iniciais. Práxis Educacional, 11(19), 119-136. 
Tirvelato, S. L. F., SILVA, R. L. F. (2011). Ensino de Ciências. São Paulo: Cengage Learning, 2011. v. $1.135 \mathrm{p}$.

UNESCO - Organização das Nações Unidas para a Educação, a Ciência e a Cultura. (2005). Década da educação das nações unidas para um desenvolvimento sustentável, 2005-2014: documento final do esquema internacional de implementação. Brasília: UNESCO, 120p. Disponível em: $<$ http://unesdoc.unesco.org/images/0013/ 001399/139937por.pdf>. Acesso em: jul. 2017.

Viecheneski, J. P., Lorenzetti, L., e Carletto, M. R. (2012). Desafios e práticas para o ensino de ciências e alfabetização científica nos anos iniciais do Ensino Fundamental. Atos e Pesquisa em Educação, 7(3), 853-876.

Vygotsky, L. S. (1988). A formação social da mente. São Paulo: Martins Fontes. 